\title{
Repensando o Ensino com Novas Tecnologias, Design Thinking e Experiência do aluno: Um Estudo Qualitativo com base em Formação Docente
}

\author{
Title: Rethinking Teaching with New Technologies, Design Thinking and Student \\ Experience: A Qualitative Study based on Teacher Education
}

César Augusto Rangel Bastos

UNIRIO

cesar.bastos@uniriotec.br

\author{
Sean Wolfgand Matsui Siqueira \\ UNIRIO \\ sean@uniriotec.br
}

\begin{abstract}
Resumo
Nas salas de aula é comum ouvir alunos reclamando de aulas monótonas e com metodologias ultrapassadas, enquanto professores reclamam da falta de motivação dos alunos. Este distanciamento entre a realidade dos alunos (imersos em uma cibercultura) com as práticas pedagógicas vem sendo pesquisado para que haja uma integração entre estes aspectos e se desenvolva uma educação de melhor qualidade. No trabalho apresentado neste artigo, investigamos três pilares para esta integração: tecnologia, Design Thinking e Experiência do Usuário. Consideramos um cenário de formação docente (curso) que explora estes três pilares. Seguimos uma abordagem qualitativa, com base em pesquisa-formação. A partir da análise do discurso dos cursistas em fóruns de discussão e relatórios textuais, apresentamos o resultado de sua construção de conhecimento em relação a estes três pilares e destacamos trechos de seus relatos que apresentam reflexões e possíveis mudanças nos conteúdos e práticas pedagógicas, bem como nos sujeitos em formação. Destacamos como principais impactos deste trabalho: o regaste da motivação de professores e alunos, a construção de conhecimento de forma crítica e criativa, e a aprendizagem mais significativa e centrada no estudante.
\end{abstract}

Palavras-Chave: Formação Docente; Design Thinking; Experiência do Usuário; Pesquisa-Formação

\begin{abstract}
In classrooms, it is common to hear students complaining about monotonous classes and outdated methodologies, while teachers complain about the students' lack of motivation. This mismatch between the students' reality (immersed in cyberculture) and pedagogical practices are subject of research aimed at promoting the integration of these aspects and developing high-quality education. In the work presented in this article, we investigate three pillars for this integration: technology, Design Thinking and User Experience. We consider a scenario of teacher training (course) that explores these three pillars. We follow a qualitative approach based on research-training. From the analysis of discourse of the course participants, we present the knowledge-building process regarding these three pillars and highlight excerpts from their reports that present thinking and possible changes in pedagogic content and practices, as well as in the individuals under training. We highlight as main impacts of this work: the rescue of the motivation of teachers and students, the construction of knowledge critically and creatively, as well as the meaningful and student-centered learning.
\end{abstract}

Keywords: Teacher Training; Design Thinking; User Experience; Research-Training.

Cite as: Bastos, C. A. R., \& Siqueira, S. W. M.. (2020). Rethinking Teaching with New Technologies, Design Thinking and Student Experience: A Qualitative Study based on Teacher Education (Repensando o Ensino com Novas Tecnologias, Design Thinking e Experiência do aluno: Um Estudo Qualitativo com base em Formação Docente). Brazilian Journal of Computers in Education (Revista Brasileira de Informática na Educação - RBIE), 28, 573-595. DOI: 10.5753/RBIE.2020.28.0.573 


\section{Introdução}

Parte dos professores desta década foi formada com base em práticas pedagógicas do século passado e não utilizaram tecnologias que os alunos utilizam hoje em sua formação, como tablets, smartphones/smartwatches e computadores. Por outro lado, os alunos cada vez mais vivem uma cultura digital, fazem uso de mundos virtuais, simuladores, redes sociais e internet no cotidiano e na sala de aula, instigando o professor a dominar a tecnologia para melhor entender a realidade e os processos de construção de conhecimento de seus alunos e adotar estratégias que promovam a criatividade e a criticidade (Ribeiro, Longaray \& Behar, 2011; Bates, 2015).

Levando em consideração que este distanciamento entre a realidade dos alunos e a prática docente pode ser um problema (por não favorecer o processo de absorção do conhecimento); este artigo foi construído como um modo de apoiar os professores a refletirem formas de inclusão desta nova realidade dos alunos em suas práticas docentes. Tais iniciativas visam possibilitar que professores reflitam sobre a importância de trazer suas aulas para o dia-a-dia dos alunos, promovendo a identificação dos mesmos com as aulas (Silva, 2005). A compreensão desta realidade de Cibercultura (contexto da pesquisa) pode refletir na prática docente de modo a promover um repensar a Educação.

Portanto, o problema abordado neste trabalho é o distanciamento entre a realidade dos alunos e a prática docente.

Partimos da tecnologia, Design Thinking (DT) e Experiência do Usuário (do inglês, User eXperience - UX) como pilares para repensar os conteúdos e as práticas educacionais. O pilar Tecnologia já vem sendo investigado como um propulsor de mudanças em diversos setores, incluindo a Educação (Ruggiero \& Mong, 2015; Tondeur, Van Braak, Ertmer \& OttenbreitLeftwich, 2017; Foulger, Graziano, Schmidt-Crawford \& Slykhuis, 2017; Huang, Spector \& Yang, 2019). Em nossa pesquisa, entendemos a importância de também se observar a Educação como um processo de design.

De acordo com Henriksen, Richardson e Mehta (2017), o design pode ser visto como uma lente teórica para Educação (Mishra \& Koehler, 2006; Kirschner, 2015; Norton \& Hathaway, 2015), pois apoia o processo de criação e de resolução de problemas. Hebert Simon traz uma definição de design que reflete sua aplicabilidade à resolução de problemas, pois "todo mundo que cria os cursos de ação que visam transformar situações existentes em preferidas faz design". Assim, fazer design é ser um agente de mudanças, é criar soluções. Por outro lado, o termo "Design Thinking" (DT) se refere ao processo cognitivo de trabalhar o design (Cross, 2011; Simon, 1969) - ou as habilidades e práticas de pensar que designers usam para criar novas ideias ou artefatos para resolver problemas na prática. Dunne e Martin (2006) distinguem design de DT, sendo DT um processo cognitivo que designers usam ao invés de artefatos que eles produzem.

Percebemos, portanto, a importância de trazer os conceitos de DT para a formação de professores, de modo a guiar as práticas docentes e atividades discentes, bem como o desenvolvimento de habilidades do processo de design. Espera-se que por meio de ferramentas, abordagens, aplicações, exemplos, teoria e estruturas específicas de DT (Norton \& Hathaway, 2015 apud Henriksen, Richardson \& Mehta, 2017), os professores reflitam sobre como aplicálos a problemas educacionais para resolvê-los. DT é geralmente considerado como a habilidade de combinar empatia, criatividade e racionalidade para analisar e encaixar soluções a contextos particulares, de modo que acreditamos promover uma melhor relação entre professores e alunos, bem como desenvolver o pensamento crítico e criativo. 
No campo da Psicologia, empatia está relacionada com a habilidade de se colocar no lugar de outra pessoa, compreender sentimentos, desejos, ideias e ações de outro indivíduo. Nesta perspectiva, a empatia é fundamental para o aprendizado (Norman, 1982). Preocupado em considerar a empatia de usuários para avaliar a usabilidade de produtos, o design thinker e psicólogo cognitivo Donald Norman utilizou, na década de 90, o termo User eXperience (UX) para identificar todos os aspectos da interação do usuário com um produto, serviço ou ambiente, ressaltando a experiência de alguém (usuário) que os use (Buley, 2013). Assim, a UX enfatiza a importância de colocar as sensações e necessidades do usuário em primeiro lugar. Nos últimos anos, os educadores e pesquisadores da Educação iniciaram uma transição para a mesma abordagem, com ênfase nas necessidades do aluno ${ }^{1}$. A UX pode ser usada na Educação para enfatizar ou reforçar o objetivo de uma interação educacional, o propósito para o aluno aprender. $\mathrm{O}$ designer administra o antes, o durante e o depois da conclusão da aprendizagem, com base no UX, e desenvolve soluções de design de experiência, da forma mais adequada, sem que a tecnologia precise determinar o formato da experiência (Raybourn, 2016). Deste modo, acreditamos que para promover uma melhor aprendizagem ao aluno é necessário incluir UX no processo educacional.

Decorre-se, então, que a questão de pesquisa é "Como estes três pilares (Tecnologia, DT e UX) podem promover a integração das práticas docentes com a realidade dos alunos?". $\mathrm{E}$, portanto, o objetivo deste estudo foi investigar a reflexão dos professores em suas práticas e as possíveis mudanças, a partir de três pilares: Tecnologia, DT e UX. Para isto, consideramos uma iniciativa de formação docente (um curso de extensão em tecnologias, DT e UX) e seguimos a abordagem de pesquisa-formação (Josso, 2004) (método de pesquisa), realçando questionamentos dos professores e instigando possibilidades para problematizar suas histórias de vida, no sentido de entender as reflexões e mudanças em suas práticas pedagógicas. Histórias de vida e/ou experiências carregam em si formas de os professores desenvolverem suas ideias, bem como se comunicar e agir para serem compreendidos pelos alunos, resultando em seus conteúdos e práticas pedagógicas e, consequentemente, nas experiências de aprendizagem. As trocas de informações e experiências entre os professores possibilitam que eles ressignifiquem seu contexto e criem novas ideias para solucionar os problemas (em sala de aula, ou qualquer outro espaço). Isto corresponde aos processos de empatia, problematização e ideação do DT. Desta forma, será possível projetar conteúdos e práticas educativas e testá-los, que seriam compatíveis com as etapas de prototipação e teste do DT. Tudo isto considerando a UX como base. A pesquisa-formação é caracterizada por contemplar a possibilidade de mudança das práticas e dos sujeitos em formação em uma perspectiva de compromisso e de reflexão da prática, possibilitando ao pesquisador e demais sujeitos envolvidos reorientarem seu trabalho (Santos \& Santos, 2015).

O restante do artigo está organizado do seguinte modo: a seção 2 descreve trabalhos relacionados, a seção 3 apresenta o planejamento do curso de formação-docente baseado em Tecnologias, DT e UX. A seção 4 descreve o processo da pesquisa-formação, enquanto a seção 5 análises complementares. Por fim, apresentamos a conclusão e sugestão de trabalhos futuros.

\section{Trabalhos Relacionados}

Foram feitos diversos levantamentos na literatura em busca de trabalhos relacionados. Partindo dos três pilares considerados como base para este trabalho (Tecnologias, DT e UX) e

\footnotetext{
${ }^{1}$ Esse processo também é conhecido como Learning Experience (LX) ou Experiência de Aprendizagem (Kilgore 2016). Neste artigo mantivemos a terminologia de UX, embora nos referimos a LX. Connie Malamed cunhou o termo "design da experiência de aprendizagem" (IDF 2016) que envolve os processos que abordam um sistema de experiências que existe dentro de um contexto cultural.
} 
considerando o contexto de Educação, iniciamos com buscas no Portal de Publicações da Comissão Especial de Informática na Educação - CEIE, da Sociedade Brasileira de Computação - SBC, onde estão os anais dos eventos da área no Brasil, bem como a Revista Brasileira de Informática na Educação (RBIE). Considerando-se que este portal contempla dois dos aspectos: Tecnologia e Educação (ou Informática e Educação), utilizamos a combinação dos termos "design thinking" e "user experience", mas só encontramos nosso trabalho anterior (Bastos \& Siqueira, 2019). Ao considerar a tradução de "user experience" como "experiência do usuário" encontramos também o trabalho de Ferreira et al. (2020). De modo a expandir o escopo da busca, consideramos apenas o termo "design thinking" e encontramos 19 trabalhos. Entretanto, dos 19 trabalhos, quatro (incluindo os dois indicados anteriormente) são relacionados a este trabalho. Estes quatro trabalhos são apresentados na Tabela $1^{2}$, de acordo com as características relevantes ao escopo desta pesquisa.

Tabela 1: Artigos relacionados encontrados no Portal de Publicações da CEIE-SBC.

\begin{tabular}{|l|l|l|l|l|l|l|l|}
\hline Citação & DT & UX & Tecnol. & Domínio específico & $\begin{array}{l}\text { Nível de } \\
\text { ensino }\end{array}$ & $\begin{array}{l}\text { Formação } \\
\text { docente }\end{array}$ & $\begin{array}{l}\text { Método de } \\
\text { pesquisa }\end{array}$ \\
\hline $\begin{array}{l}\text { (Bastos \& } \\
\text { Siqueira, 2019) }\end{array}$ & Sim & Sim & Não & Formação docente & Todos & Sim & $\begin{array}{l}\text { Pesquisa- } \\
\text { formação }\end{array}$ \\
\hline $\begin{array}{l}\text { (Ferreira et al., } \\
\text { 2020) }\end{array}$ & Sim & Sim & Sim & $\begin{array}{l}\text { Desenvolvimento de } \\
\text { software }\end{array}$ & $\begin{array}{l}\text { Ensino } \\
\text { básico }\end{array}$ & Não & Multimétodo \\
\hline $\begin{array}{l}\text { (Oliveira \& } \\
\text { Andrade, 2019) }\end{array}$ & Sim & Não & Não & Ensino de Matemática & $\begin{array}{l}\text { Ensino } \\
\text { fundamental }\end{array}$ & Sim & $\begin{array}{l}\text { Não } \\
\text { explicitado }\end{array}$ \\
\hline $\begin{array}{l}\text { (Silva e } \\
\text { Cavalcante, 2016) }\end{array}$ & Sim & Não & Sim & Ciências Biológicas & $\begin{array}{l}\text { Ensino } \\
\text { superior }\end{array}$ & Sim & $\begin{array}{l}\text { Não } \\
\text { explicitado }\end{array}$ \\
\hline
\end{tabular}

Nosso trabalho anterior (Bastos \& Siqueira, 2019) descreve um estudo com foco em uma formação docente no contexto de Design Instrucional (DI), também chamado de projeto instrucional, baseado no modelo $\mathrm{ADDIE}^{3}$. Apenas na última etapa daquele curso, apresentamos os conceitos de DT e UX de maneira introdutória e solicitamos que os cursistas repensassem o DI do minicurso que eles desenvolveram nas etapas anteriores. Entretanto, tecnologia não foi contemplada como parte do escopo da formação docente, o foco dos docentes estava no DI, enquanto DT e UX foram apresentados apenas de maneira introdutória para apoiar um outro olhar para o processo de DI. Além disto, as histórias de vida e/ou experiências que levaram os professores a desenvolverem suas ideias, suas reflexões, não ficaram evidenciadas, restringindo a profundidade da pesquisa-formação.

Ferreira et al. (2020) apresentam o desenvolvimento, aplicação e avaliação de uma unidade instrucional que incorpora o ensino de competências de design de interfaces de usuário no ensino de computação. Também seguem o design instrucional ADDIE para apoiar no desenvolvimento da unidade instrucional, enquanto o DT e UX são utilizados no contexto do conteúdo do curso ensinado a alunos, cujo foco é a Interface de Usuário no desenvolvimento de aplicativos móveis. O escopo é o Ensino Fundamental. Os dados dos alunos são coletados por meio de avaliação no desempenho, testes e questionários respondidos. Portanto, não se trata de uma formação docente e o método de pesquisa é primordialmente estudo de caso (embora os autores indiquem multimétodo), não se referindo, portanto, a uma pesquisa-formação.

\footnotetext{
2 Incluímos "método de pesquisa" na Tabela 1, mas consideramos o que os autores dos trabalhos explicitaram. Não entramos no julgamento de mérito e corretude. Também é importante ressaltar que a tabela apresenta uma classificação muito resumida dos trabalhos, para efeitos de comparação com o escopo deste artigo, não ressaltando as especificidades e contribuições de cada trabalho.

${ }^{3}$ Embora existam várias propostas de modelo para DI, o modelo ADDIE - Analysis, Design, Development, Implementation and Evaluation, proposto por Clark (2014), é o mais utilizado.
} 
Oliveira e Andrade (2019) apresentam uma proposta de um modelo de formação de professores com base em DT, onde foi feito um estudo com 13 professores no contexto de ensino de matemática para o ensino fundamental. Os autores não abordam UX e não fica explícito o método de pesquisa adotado.

Silva e Cavalcante (2016) trabalham os processos didáticos com DT, em uma estrutura didática que dialoga com ideias da arquitetura pedagógica e orquestração de processos de ensino. Os autores enfocam na formação de alunos de licenciatura no contexto de Ciências Biológicas, mas não discutem UX. O método de pesquisa não está explicitado, mas observa-se a construção da pesquisa com base nas vivências, experiências e demandas dos sujeitos envolvidos.

Também foram realizadas pesquisas nas seguintes bases: ScienceDirect, Springer, ACM e IEEE. Não foram encontrados trabalhos que apresentassem pesquisa-formação contemplando novas tecnologias, DT e UX. Considerando-se DT no contexto educacional, foram encontrados 29 trabalhos na ScienceDirect, 40 trabalhos na Springer, 39 trabalhos na ACM e 23 trabalhos na IEEE. Devido às funcionalidades das ferramentas de busca específicas dessas bases, em alguns casos foi utilizado "design thinking" no título e "education" no abstract. Os trabalhos estão voltados principalmente para o uso de DT para apoiar atividades de uma disciplina/curso ou de uma instituição de ensino como um todo. Também se observa DT para apoiar o desenvolvimento de software educacional. Finalmente, há ainda trabalhos voltados para o ensino de design ou mesmo ensino de DT. Os trabalhos encontrados mais relacionados a esta pesquisa são apresentados na Tabela 2 .

As buscas por trabalhos que contemplam UX no contexto educacional não retornaram resultados no contexto de enfatizar ou reforçar a interação educacional, mas sim de melhorar o desenvolvimento de Interfaces de Usuário ou de ensinar UX. Utilizar apenas o termo "user experience", sem a sigla correspondente UX, tornou-se inviável de ser processada pelo volume de trabalhos retornados (105 resultados na ScienceDirect, 8.462 na Springer, 131.799 na ACM e 813 na IEEE).

Tabela 2: Trabalhos mais relacionados resultantes do levantamento realizado na ScienceDirect, Springer, ACM e IEEE

\begin{tabular}{|l|l|l|l|l|l|l|l|}
\hline Citação & DT & UX & Tecnol. & $\begin{array}{l}\text { Domínio } \\
\text { específico }\end{array}$ & $\begin{array}{l}\text { Nível de } \\
\text { ensino }\end{array}$ & $\begin{array}{l}\text { Formação } \\
\text { docente }\end{array}$ & Método de pesquisa \\
\hline $\begin{array}{l}\text { (Aguado et al., } \\
\text { 2014) }\end{array}$ & Sim & Não & Sim & $\begin{array}{l}\text { Design } \\
\text { Instrucional }\end{array}$ & Extensão & Sim & Não explicitado \\
\hline $\begin{array}{l}\text { Andersen \& } \\
\text { Pitkänen, 2018) }\end{array}$ & Sim & Não & Sim & FabLabs & $\begin{array}{l}\text { Professores } \\
\text { em geral }\end{array}$ & Sim & $\begin{array}{l}\text { Estudo de caso com } \\
\text { método etnográfico }\end{array}$ \\
\hline $\begin{array}{l}\text { (Henriksen, } \\
\text { Richardson \& } \\
\text { Mehtab, 2017) }\end{array}$ & Sim & Não & Sim & $\begin{array}{l}\text { Tecnologias } \\
\text { Educacionais }\end{array}$ & Mestrado & Sim & Estudo de caso \\
\hline \begin{tabular}{l} 
(Stefaniak, 2020) \\
\hline
\end{tabular} & Sim & Sim & Não & N.A. & N.A. & Não & Não explicitado \\
\hline
\end{tabular}

Aguado et al. (2014) apresentam um estudo baseado na formação docente, onde designers instrucionais reveem seus cursos com base em DT e empreendedorismo. É um trabalho parecido com o realizado por (Bastos \& Siqueira, 2019), embora não explicitem o método de pesquisa (indicam o uso de métodos quantitativos e qualitativos, mas não apresentam nenhum detalhamento). Os autores discutem algumas tecnologias educacionais durante o curso, mas não detalham como DT foi explorado. São observadas menções a experiência do aluno, mas o trabalho não se baseia na fundamentação de UX.

Andersen e Pitkänen (2018) apresentam um estudo sobre como acontece o empoderamento dos professores com base em DT e FabLabs. Os autores não mencionam UX e, 
embora seja um trabalho com foco na formação docente, não é uma pesquisa-formação e sim um estudo de caso com base em etnografia.

Henriksen, Richardson e Mehtab (2017) apresentam um estudo qualitativo, caracterizado como estudo de caso, embora se observe o contexto de pesquisa-formação, com alunos de um curso de mestrado em Tecnologias Educacionais, organizado em torno do uso de DT para abordar problemas educacionais relacionados à prática. A estruturação do curso é parecida com o descrito neste artigo, com leituras e discussões, projetos e um artigo (relatório) de reflexão. Embora o estudo tenha similaridades com o apresentado neste artigo, não foram observadas menções às tecnologias (provavelmente porque são exploradas em outras disciplinas) e UX. Vale destacar que as análises de discurso são realizadas e apresentadas de maneira exclusivamente baseada em trechos do texto, diferente do que trazemos em nosso trabalho.

Stefaniak (2019) apresenta um framework conceitual baseado em DT, teoria geral de sistemas e na literatura de DI de modo a apoiar as práticas de DI. O framework tem menções a trabalhos de UX em sua concepção, bem como tecnologias, embora não explorem ou detalhem tais conceitos em seu trabalho. Não é observado o uso do framework em formação docente, apesar do foco do artigo. O método de pesquisa não é explicitado, embora se observe um trabalho propositivo baseado na literatura.

\section{A Formação Docente baseada em Tecnologias, DT e UX}

Para a formação docente, organizamos o curso "Novas Tecnologias com Experiência do Aluno: Design Thinking para Educadores", com a proposta de promover uma discussão de novas tecnologias, bem como as abordagens de DT e UX, para professores interessados em inovação em suas respectivas práticas pedagógicas. Esse curso foi organizado em quatro etapas, considerando exposição/disponibilização de conteúdo, reflexões sobre aplicação do que foi aprendido em sua realidade, interações entre os participantes e desenvolvimento de relatórios. Cada uma das três primeiras etapas tem uma avaliação (respectivamente AD1, AD2 e AD3) e, ao final do curso (quarta etapa), foi pedido que os alunos fizessem um relatório final como atividade opcional.

O curso é organizado de modo que, na primeira etapa, os participantes (cursistas) devem se apresentar, contar suas experiências com uso de tecnologias (semana 1) e, após leituras e discussões sobre tecnologias inovadoras nos dias atuais (semana 2) e usos no contexto educacional (semana 3), devem fazer uma avaliação (AD1) através de um relatório sobre o uso de algumas dessas tecnologias na educação, seja em sala de aula, como aluno, em treinamentos, na orientação pedagógica ou gestão educacional (semana 4). A primeira etapa, de apresentação e compartilhamento de histórias, tem como objetivo começar a despertar a visão de Empatia, de modo que também começa a trabalhar DT (apesar dos conceitos ainda não serem introduzidos nesta etapa). Além de explorar as tecnologias educacionais, esta etapa visa discutir tecnologias inovadoras que estão presentes em nosso dia-a-dia, que fazem parte de nossa Cultura Digital e muitas das vezes não observamos. Neste sentido, a proposta é construir um conhecimento sobre as tecnologias que fazem parte das vidas das pessoas, sejam professores ou alunos, e então discutir possibilidades de trazê-las para o contexto de aula ou escolar. E ainda nesta etapa, começamos a trabalhar as fases de Definir o Problema e Idealizar de DT, sem efetivamente apresentar os conceitos de DT.

$\mathrm{Na}$ segunda etapa do curso, o foco é DT, discutindo conceitos e o processo de Empatizar, Definir o Problema, Idealizar, Prototipar e Testar. Estas fases são do Modelo de DT de 
Stanford $^{4}$, que seguimos como base. Após estudo do material disponível no curso, os cursistas devem discutir sobre as possibilidades de aplicação de DT na educação. Na avaliação AD2, a atividade é um planejamento, ou indicação de uma experiência considerada boa, sobre o uso de DT na educação. Nesta AD2, os cursistas devem registrar suas experiências com DT, como se sentem utilizando DT na educação. Aqui os alunos já entendem as fases de DT e podem explorar todas estas fases (ou pelo menos as três primeiras, caso não tenham a oportunidade de experimentar na prática) na atividade de avaliação AD2.

$\mathrm{Na}$ terceira etapa do curso, o foco é UX. Após estudo do material disponível no curso, os cursistas devem discutir sobre as possibilidades de aplicação de UX na educação. Aqui observase que a experiência nas etapas anteriores do curso é importante para o entendimento do material e das atividades. Isto porque a base da UX está no contexto tecnológico e é necessário contextualizar na educação. Para auxiliar nesta contextualização, parte do material traz discussões e exemplos do contexto educacional. A avaliação AD3 é dividida em duas partes, onde cada cursista deve comentar na primeira parte como aproveitar DT e UX na sua prática pedagógica (ou alguma atividade envolvendo o contexto educacional) e também fazer uma proposta de uso de DT e UX de acordo com seu contexto de trabalho e/ou curso. Aqui os alunos são conduzidos a explorar as fases de DT, já associando com as atividades de UX.

Ainda na terceira etapa do curso, os cursistas devem, como segunda parte da avaliação AD3, comentar sobre propostas de colegas de turma apresentadas na primeira parte da AD3. O objetivo é promover as trocas entre os cursistas e com isto consolidar as reflexões sobre as práticas educacionais, ao avaliar se cada proposta é aplicável no contexto dos outros participantes e discutir o que pode ser alterado para que isto seja possível.

Finalmente, na quarta etapa, os cursistas devem rever o que foi estudado no curso e desenvolver um relatório final, de formato livre, contando sua experiência no curso. Adicionalmente, é solicitado que os cursistas incluam no relatório final, as seguintes informações: nome, área de atuação, formação (ou área de conhecimento) e se tinham conhecimento prévio ou não de DT e UX antes do curso. Do ponto de vista da pesquisa realizada, esta etapa é considerada a mais importante porque promove a consolidação das reflexões de cada docente em formação em relação a suas práticas pedagógicas e possibilita entender as histórias de vida e/ou experiências de cada docente. Aqui é possível perceber mais facilmente as mudanças das práticas e dos sujeitos em formação.

O estudo foi realizado através da turma de abril a maio de 2018 do curso gratuito de extensão do CEDERJ "Novas Tecnologias com Experiência do Aluno: Design Thinking para Educadores", de formação de professores/tutores em educação online.

O público alvo do curso foi formado por professores e profissionais da área de educação, alguns com mais de vinte anos de magistério e outros recém-formados, todos procurando cursos de formação e capacitação de professores com uso de novas tecnologias digitais da informação e comunicação (TDIC) para aprimorar sua prática pedagógica. A turma de 2018 teve 175 inscritos, sendo que 82 participaram do curso $^{6}$. A média de idade dos participantes foi de 42

\footnotetext{
${ }^{4}$ Watson (2015) indica que há vários modelos ou propostas para DT, dos quais destacamos o Modelo de DT de Stanford - https://dschool.stanford.edu/resources/design-thinking-bootleg, que prevê cinco fases: Empatia, Definição do Problema, Ideação, Prototipação e Teste; e a proposta da IDEO para o contexto de Educação http://www.dtparaeducadores.org.br/site/material/, que também considera cinco etapas ou fases, que podem ser vistas como diretamente mapeáveis para a de Stanford: Descoberta, Interpretação, Ideação, Experimentação e Evolução. Outros modelos indicam a primeira fase como Enfatizar e a terceira fase como Brainstorming, por exemplo. Utilizaremos a terminologia do modelo de DT de Stanford neste artigo.

${ }^{5}$ Fundação CEDERJ - Extensão: http://cederj.edu.br/extensao/

${ }^{6}$ Por ser um curso gratuito, há um alto número de inscrições, dos quais nem todos selecionados participam do curso posteriormente.
} 
anos, sendo $72 \%$ do sexo feminino. A seleção dos participantes do curso foi realizada por uma equipe de profissionais da instituição, com base em critérios estabelecidos em edital, de acordo com o currículo, dando-se prioridade por profissionais ligados à Educação. A equipe de coordenadores, professores e tutores do curso não teve participação no processo de seleção.

Foi utilizado o ambiente de aprendizagem da instituição, baseado no Moodle. As interações foram realizadas através de fóruns, enquanto os relatórios eram atividades de entrega/envio de arquivo. Do total de participantes, 54 foram aprovados e apenas 46 fizeram o relatório final ${ }^{7}$. Os nomes foram omitidos para preservar a privacidade dos cursistas. Observa-se que a média de idade dos participantes que entregaram o relatório final se manteve em torno dos 42 anos, sendo 67,4\% do sexo feminino. De acordo com as informações no relatório final, 29 são docentes $(63,0 \%)$ e 5 orientadores ou coordenadores pedagógicos, enquanto os demais são estudantes, programadores, produtores de mídia ou não especificaram ${ }^{8}$. Os níveis de ensino em que trabalham (quando se aplica) são os mais variados, não apresentando diferença significativa entre os mesmos. A maioria dos respondentes é formada em Pedagogia $(23,9 \%)$ ou Licenciatura $(32,6 \%)$, sendo que a área de Formação é bastante variada, incluindo História, Ciências, Desenho técnico, Filosofia, Letras, Matemática, Artes, Química, Física, Tecnologia, entre outras.

De acordo com os 46 relatórios finais, 26 cursistas (56,5\%) nunca tinham ouvido falar de DT, $18(39,1 \%)$ já tinham ouvido falar ou conheciam no contexto empresarial e 2 já tinham ouvido falar no contexto educacional, embora não tivessem aplicado ainda. E sobre UX, 40 $(86,9 \%)$ nunca tinham ouvido falar formalmente sobre isso e 6 já tinham ouvido falar apenas no contexto tecnológico.

\section{O Processo da Pesquisa-Formação}

Apresentamos um estudo qualitativo, onde os participantes-professores usam seus conhecimentos e experiências para, através de interações em fóruns e os relatórios apresentados, construírem um repensar de seus conteúdos e práticas educacionais, do ponto de vista de sua própria percepção e de seus alunos. Todas as interações dos cursistas, incluindo as mensagens postadas nos fóruns da turma, bem como os relatórios enviados, em especial o relatório final, serviram de base para a observação da construção do conhecimento dos cursistas em relação aos três pilares considerados nesta pesquisa: Tecnologia, DT e UX. Também permitiram observar e analisar as mudanças das práticas e dos sujeitos em formação, que são ressaltados através de alguns trechos dos relatos. A ideia desta abordagem qualitativa foi compartilhar as vozes dos cursistas por meio de suas falas (participações nos fóruns e relatórios), trazendo a construção das mudanças de suas práticas e até mesmo de suas percepções gerais e em suas vidas pessoais. A Tabela 3 resume os aspectos da pesquisa científica, baseado em Filippo, Pimentel e Wainer (2011).

Tabela 3: Aspectos da metodologia da pesquisa científica adotados neste trabalho

\begin{tabular}{|l|l|}
\hline Aspecto & Descrição \\
\hline Abordagem da pesquisa & Pesquisa qualitativa \\
\hline Posição epistemológica & Interpretativista \\
\hline Método de pesquisa & Pesquisa-formação \\
\hline
\end{tabular}

\footnotetext{
${ }^{7} \mathrm{O}$ relatório final não era obrigatório para a aprovação na disciplina.

${ }^{8}$ Vale ressaltar que as informações pessoais e profissionais dos alunos contidas nos relatórios finais não necessariamente são equivalentes às das fichas de inscrição no curso. Tais informações foram solicitadas no relatório final, de modo opcional, para que apoiassem as análises desta pesquisa. Deste modo, podem ter informações incompletas ou ausentes em alguns dos itens solicitados.
} 


\begin{tabular}{|l|l|}
\hline Finalidade & $\begin{array}{l}\text { Explorar a construção de conhecimento, reflexões dos professores e mudanças em } \\
\text { suas práticas (a partir dos três pilares considerados: Tecnologia, DT e UX) }\end{array}$ \\
\hline Técnica de coleta de dados & $\begin{array}{l}\text { Interações dos alunos no ambiente de aprendizagem utilizado para a formação } \\
\text { docente (Moodle), incluindo as mensagens postadas nos fóruns da turma, bem como } \\
\text { os relatórios enviados }\end{array}$ \\
\hline Técnica de análise de dados & Análise do discurso \\
\hline $\begin{array}{l}\text { Técnicas de apresentação } \\
\text { dos resultados da análise }\end{array}$ & Nuvens de palavras, mapas mentais de reflexões, extratos de trechos de discurso \\
\hline
\end{tabular}

Utilizamos nuvens de palavras (NP) para nos apoiar a trazer uma ideia de como ocorreu a construção do conhecimento dos cursistas. Nuvens de palavras (DePaolo \& Wilkinson, 2014) são imagens populares e divertidas, parecidas com nuvens formadas com palavras. Uma NP é gerada a partir de um texto ou lista de palavras, enquanto o tamanho de cada palavra na nuvem indica sua frequência, considerado como um indicador da relevância de determinada temática na totalidade do texto. A Figura 1 mostra a $\mathrm{NP}^{9}$ criada a partir das mensagens trocadas nos fóruns de discussão sobre tecnologia ( $1^{\mathrm{a}}$ etapa do curso).

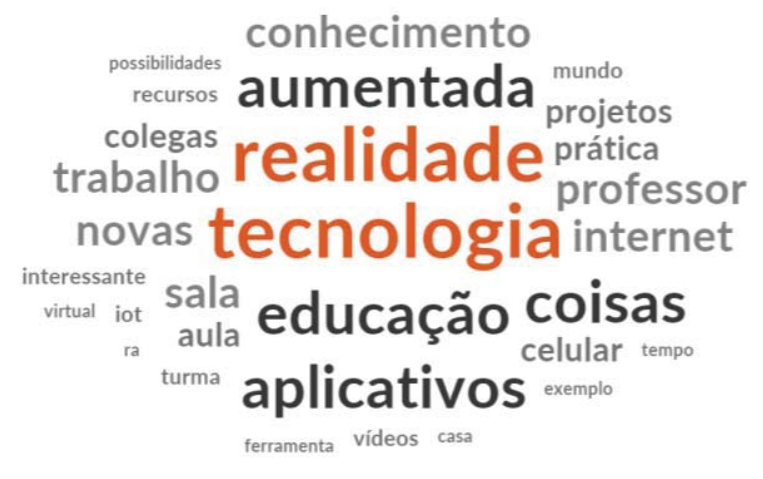

Figura 1: Nuvem de palavras dos fóruns sobre Tecnologia.

Na NP dos fóruns de discussão sobre Tecnologia (Figura 1), observamos que, conforme esperado, tecnologia é uma palavra muito utilizada. Realidade também aparece bem evidenciada, o que se justifica por ser um termo utilizado para retratar a realidade das pessoas, mas também porque os alunos apreciaram e discutiram bastante sobre "realidade aumentada", o que pode ser observado pelo termo "aumentada" aparecer com destaque também. Outro termo relacionado é "ra", que é a sigla para "realidade aumentada", que também aparece na NP, embora com menos destaque.

Algumas palavras na NP da Figura 1 são relacionadas a Educação: conhecimento, colegas, projetos, prática, professor, sala, aula (estes dois últimos formando "sala de aula"), turma e exemplo. Também há palavras que remetem a outras tecnologias, como recursos, internet, virtual (devido ao tema realidade virtual), iot (sigla para internet das coisas), coisas (que pode estar associada a internet ou algo genérico), celular, aplicativos, vídeos e ferramenta. Outras palavras estão associadas ao dia-a-dia do professor, como mundo, tempo e casa. "Novas" é uma palavra que surgia juntamente com tecnologias, fazendo referência a discussões sobre novas tecnologias. Finalmente, algumas palavras que aparecem registram a motivação dos professores, como possibilidades e interessante. Assim, mesmo que de modo bem resumido, é possível observar a construção dos conceitos relacionados, as reflexões e o início do repensar os conteúdos e práticas.

\footnotetext{
${ }^{9}$ As NP geradas para este trabalho foram construídas com a ferramenta NVivo e consideraram a frequência de palavras simples (unigramas), com remoção de stopwords e um dicionário simples de sinônimos. Foram construídas com as 30 palavras mais frequentes.
} 
Podemos analisar o fórum voltado para discussão de tecnologias na educação também através de uma NP (Figura 2). Vale ressaltar que este fórum de Tecnologia na Educação foi feito após os outros de tecnologia.

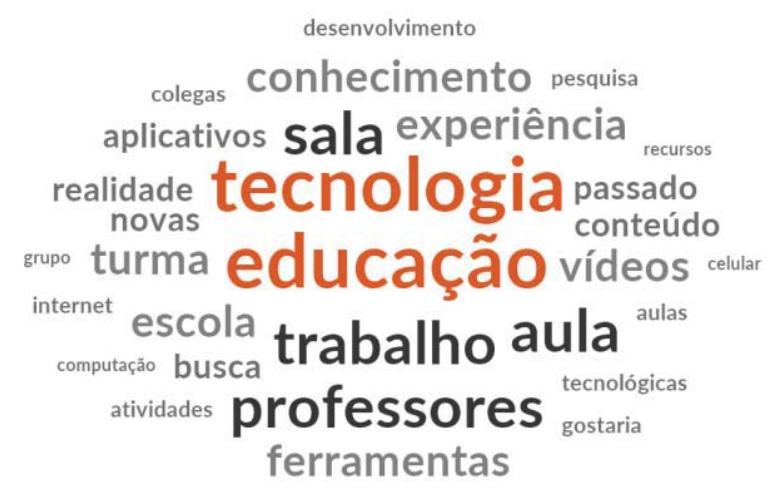

Figura 2: Nuvem de palavras do fórum sobre Tecnologia na Educação.

Nesta NP do fórum de discussão sobre tecnologias na educação (Figura 2), observa-se que as duas palavras principais são justamente "tecnologia" e "educação", seguidas de "sala" e "aula" (que formam "sala de aula"), trabalho, aula e professores, todos eles trazendo o contexto da educação, ou seja, os cursistas discutiam como explorar as tecnologias presentes em nosso dia-a-dia neste contexto, como adaptar os conteúdos e práticas pedagógicas trazendo a tecnologia como parte deste universo. Outras palavras complementam esta construção, como desenvolvimento, pesquisa, experiência, grupo, conteúdo, computação, atividades etc.

De modo a explorar mais profundamente como os cursistas refletiram suas práticas e desenvolveram suas ideias em relação à tecnologias na educação, apresentamos um mapa mental (Figura 3) com base nas reflexões sobre tecnologias na educação, que foram descritas nos relatórios finais dos cursistas. Segundo Buzan (2005), um mapa mental é um método de análise que permite tomar notas, planificar os pensamentos de uma maneira criativa através de imagens, símbolos, cores, gráficos e palavras. Propomos um tipo especial de mapa mental, que denominamos de mapa mental de reflexões (MMR), para apoiar na apresentação das reflexões dos docentes em relação aos pilares considerados nesta pesquisa. O MMR traz não apenas palavras, mas sim reflexões. Destacamos no $\mathrm{MMR}^{10}$ da Figura 3 trechos dos textos dos cursistas que são complementares, de modo a dar uma ideia da riqueza das discussões, da apropriação do conhecimento e sua aplicação em cenários reais, não sendo, portanto, uma lista exaustiva. Observamos que os cursistas refletiram sobre seus conteúdos e práticas pedagógicas e as modificaram com base nas experiências cotidianas e as novas tecnologias. Acreditamos que os trechos dos relatos sejam adequados para motivar a reflexão do leitor, bem como possibilitar a percepção da formação dos cursistas no contexto da pesquisa-formação.

\footnotetext{
${ }^{10}$ Os MMR apresentados neste trabalho foram criados com base em codificação manual dupla dos textos dos relatórios finais dos cursistas, considerando menções a assuntos voltados aos pilares tecnologia, DT e UX, destacando-se um conjunto complementar.
} 


\section{Foi importante porque pude perceber que há um grande interesse por parte dos profissionais da Educação em sair do lugar comum e se lançar na construçăo de novos caminhos, tendo como} pavimentaçăo, agora, as tecnologias e suas vertentes.

Aprendemos neste curso o valor do uso das tecnologias no dia a dia, e percebemos seu dinamism na vida das pessoas, incluindo lot (Internet das Coisas).

Faço uso da Aprendizagem Ativa, Ensino Híbrido e sala de aula invertida: os alunos pesquisam, trocam arquivos e fazem seus exercicios on line através de vários sites: Facebook, Go Conqr, blogs, Google, Gmail, Wikipedia, Whatsapp

As redes de relacionamentos como whatsApp, Facebook, Instagran e outras podem ser acessadas como ferramentas na sala de aula quando orientadas pelos professores como atividade escolar.

Este aplicativo gratuito (Padlet) facilita a montagem de painéis e murais com elementos colhidos diretamente das pastas pessoais ou da internet.

Os óculos de RV feito de papelão que pode ser facilmente confeccionado com materiais baratos ou de reciclagem, assuntos ventilados sobre robótica nos fóruns, site para construir jogos virtuais junto com os alunos, uso do Ardruino para conectar equipamentos smarts à web, apps de geståo de conteúdo e compartilhamento de arquivos, plataforma virtual de estudos, usar Storytelling como ferramenta de mapeamento das preferèncias dos alunos...

A RA pode potencializar o processo educativo com recursos de óculos de RA, em livros, por exemplo, fazendo com que o conteúdo seja compreendido com maior veracidade, uma vez que além da leitura (ou sem ela) seria possivel assistir o tema estudado em 3D. Poderia permitir a manipulaçåo de imagem em todos os ângulos, evitando possiveis erros durante o processo de criaçăo, entre tantas outras possibilidades.

\begin{tabular}{|c|}
\hline $\begin{array}{l}\text { Destaquei a plataforma Kahoot, nela é possivel criar } \\
\text { quizzes a partir da interação. Porque não uma } \\
\text { avaliaçăo formal através dessa plataforma ?!?! } \\
\text { Acredito que os alunos estariam mais relaxados } \\
\text { diante de um ambiente que eles dominam - afinal } \\
\text { de contas papel e caneta, hoje, é coisa da escola. }\end{array}$ \\
\hline $\begin{array}{l}\text { Algumas experièncias com App-learning tem me } \\
\text { chamado a atençăo por mostrarem-se muito } \\
\text { favoráveis na mediação de práticas educativas. Cito } \\
\text { como exemplo a utilização de aplicativos de cursos } \\
\text { de idiomas, podcasts de assuntos diversos, desde } \\
\text { clubes de leitura até panoramas de debates } \\
\text { históricos, entre outros gêneros educativos. } \\
\text { Simulados, testes avaliativos agora também sâo } \\
\text { possiveis em plataformas online... E o que dizer dos } \\
\text { livros em formato digital - e-books -, que ganham } \\
\text { mais adeptos na contemporaneidade. }\end{array}$ \\
\hline
\end{tabular}

Abranjo aqui além do conceito de inclusåo, o de midias digitais ao propor que meus alunos com ou sem deficiència possam estar nesse universo virtual que os acolhe os coloca em equivalencia. Para quem nâo sabe um aluno cego pode utilizar essa ferramenta com o auxilio de um leitor de tela, um software de tecnologia assistiva que utiliza o retorno sonoro como matriz semiótica.
Tudo aquilo que nos foi oferecido representou um mudança de paradigma em relaçăo às novas tecnologias que surgiram na sociedade nos últimos tempos, esclarecendo o funcionamento de inúmeros aparelhos e funcionalidades que eståo presentes no nosso cotidiano, sem que, muitas vezes, tenhamos percebido isso.

Adquiri muitas experièncias e recursos (hoje tenho uma pasta só para jogos no meu Laptop).

Agregando outras ferramentas como Realidade Aumentada, imaginamos empolgantes aulas de biologia e sistema solar com imagens perfeitas sendo projetadas na palma da måo dos alunos.

Sites de pesquisas encurtam as tarefas, abreviam o tempo e economizam papel.

Podemos juntos ao alunato inserirmos textos $\mathrm{e}$ figuras 3D para serem usadas na tecnologia RA em sala.

Grande parte dos aplicativos e ferramentas săo gratuitos ou de fácil acesso, isso facilita demais na realidade financeira de nossas escolas e bate de frente com os argumentos pessimistas do tipo: "Isso é bonito no projeto, mas nas escolas sucateadas da rede pública fica inviável".

Quando apresentamos um mapa mental estamos utilizando ferramentas do DT, repassamos ideias, tarefas e conceitos de forma visual a partir de uma palavra. Com o Método Cornell de anotaçőes criativas, os alunos além de desenhar, escrever, organizam conteúdos da forma que queiram e também permitem fazer fichamentos de leituras $e$ pesquisas de palavras chaves e conceitos. Os Padlets ou murais colaborativos permitem compartilhar com grupos e fornecer textos, fotos e outros conteúdos.

Eis as propostas que enriqueceram minhas aspiraçర̄es como futuro profissional da Educaçăo: gamificaçăo, realidade virtual, realidade

aumentada, aplicativos, fotografia, criaçåo de sites e blogs, redes sociais criativas, quizz, revistas eletrônicas, plataformas de pesquisas e etc.

Post-lt, Padlet, VideoScribe, Kahoot, Canvas, Tes Blendspace Teach, Go Conqr, Todays Meet, Lucidchart, Storyboard That, Ethnocorder, Autodesk HomeStyler, Smaply, Bram-Reactrons e FlipCharts.

Dentre as várias ferramentas uma em especial me chamou a atençăo: "Mapeando a Jornada". Com ela é possivel de forma dinâmica e estrutural extrair informaçøes importantes para problematizaçôes, assim como para propostas de resoluçø̋es baseadas em percepçరిes próprias do usuário e suas experièncias diárias junto às escolas.

Figura 3: MMR dos cursistas sobre Tecnologia na Educação. 
Similarmente às análises do pilar Tecnologia, observamos a construção do conhecimento de DT pelos cursistas através de uma NP resultante das mensagens do fórum DT na Educação (Figura 4).

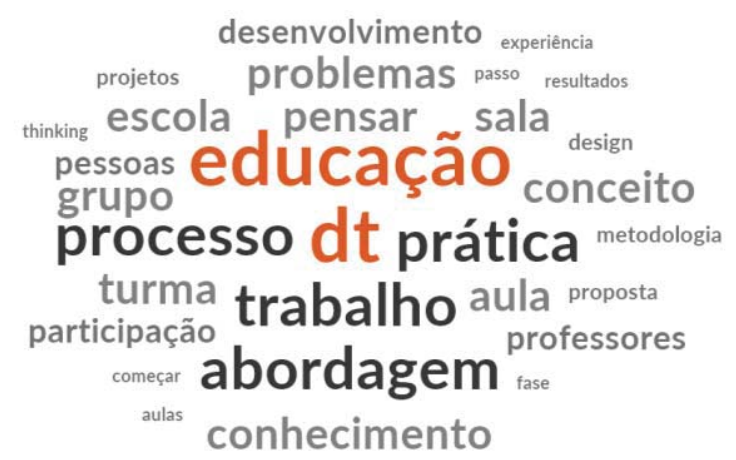

Figura 4: Nuvem de palavras do fórum DT na Educação.

Conforme esperado (Figura 4), "DT" e "educação" são as duas principais palavras que ocorrem no Fórum. Na NP aparecem ainda "design" e "thinking", mas também abordagem, processo, conceito, metodologia, fase e passo, que remetem diretamente a DT, pois discute-se o conceito, bem como suas fases. Algumas outras palavras remetem ao conceito de DT, tais como problemas (pois DT ajuda a entender e lidar com problemas), projetos, desenvolvimento e resultados (pois DT ajuda no desenvolvimento de projetos), pessoas, grupo e turma (porque DT tem esta visão nas pessoas envolvidas, através da fase Empatia), participação e grupo (porque DT envolve a colaboração) e pensar (que vem do Thinking, uma vez que DT apoia na criação, no pensar). Finalmente, observam-se as palavras que remetem à Educação, como experiência, problemas, projetos, escola, sala, conceito, processo, prática, turma, participação, trabalho, aula, proposta, professores, abordagem, aulas e conhecimento. Uma palavra interessante na NP (Figura 4) é "começar", que indica a motivação dos cursistas em começar a aplicar DT em suas práticas pedagógicas (bem como no trabalho e vidas pessoais em geral).

O MMR da Figura 5 apresenta trechos dos textos dos cursistas sobre DT na Educação extraídos dos relatórios finais. Os trechos foram selecionados de modo a apresentar visões complementares e não tem por objetivo ser uma lista exaustiva. Através deste mapa mental de reflexões, verificamos as reflexões dos cursistas e as mudanças em suas práticas e nos sujeitos envolvidos. Também é possível observar a empolgação dos cursistas em relação a DT na Educação. 


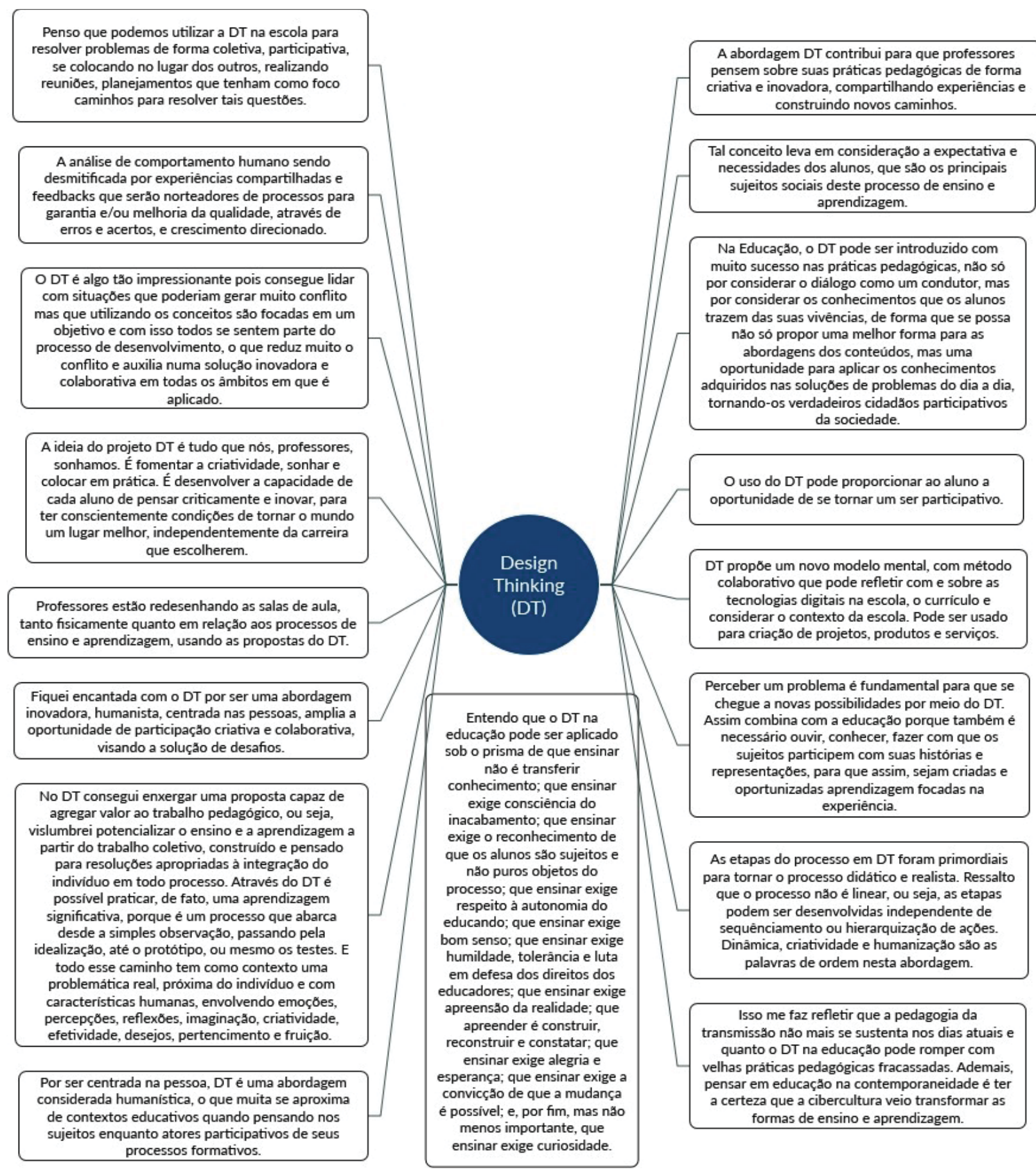

Figura 5: MMR dos cursistas sobre DT na Educação.

A NP do fórum UX na Educação (Figura 6) também permite ter uma ideia da construção do conhecimento pelos cursistas neste assunto. Novamente, observa-se o destaque para as palavras principais UX e educação, tema do fórum. Além das palavras que trazem o contexto de educação, é possível observar palavras como relação, ouvir, propósito, usuário, gente, meio, contexto, relação, interação e produto, que reforçam características de UX. 


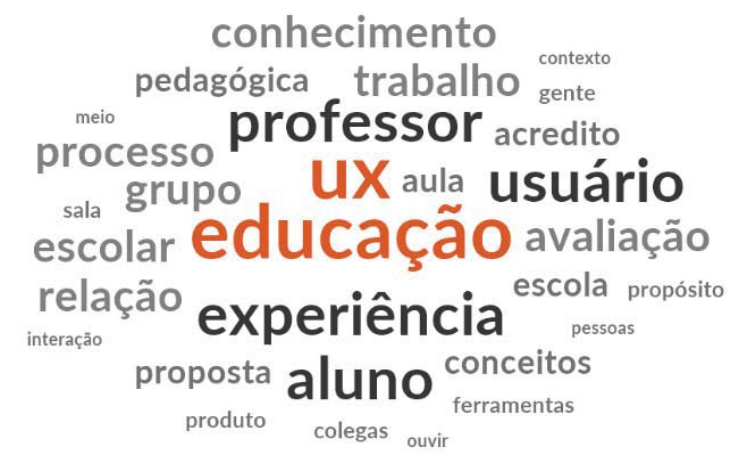

Figura 6: Nuvem de palavras do fórum UX na Educação.

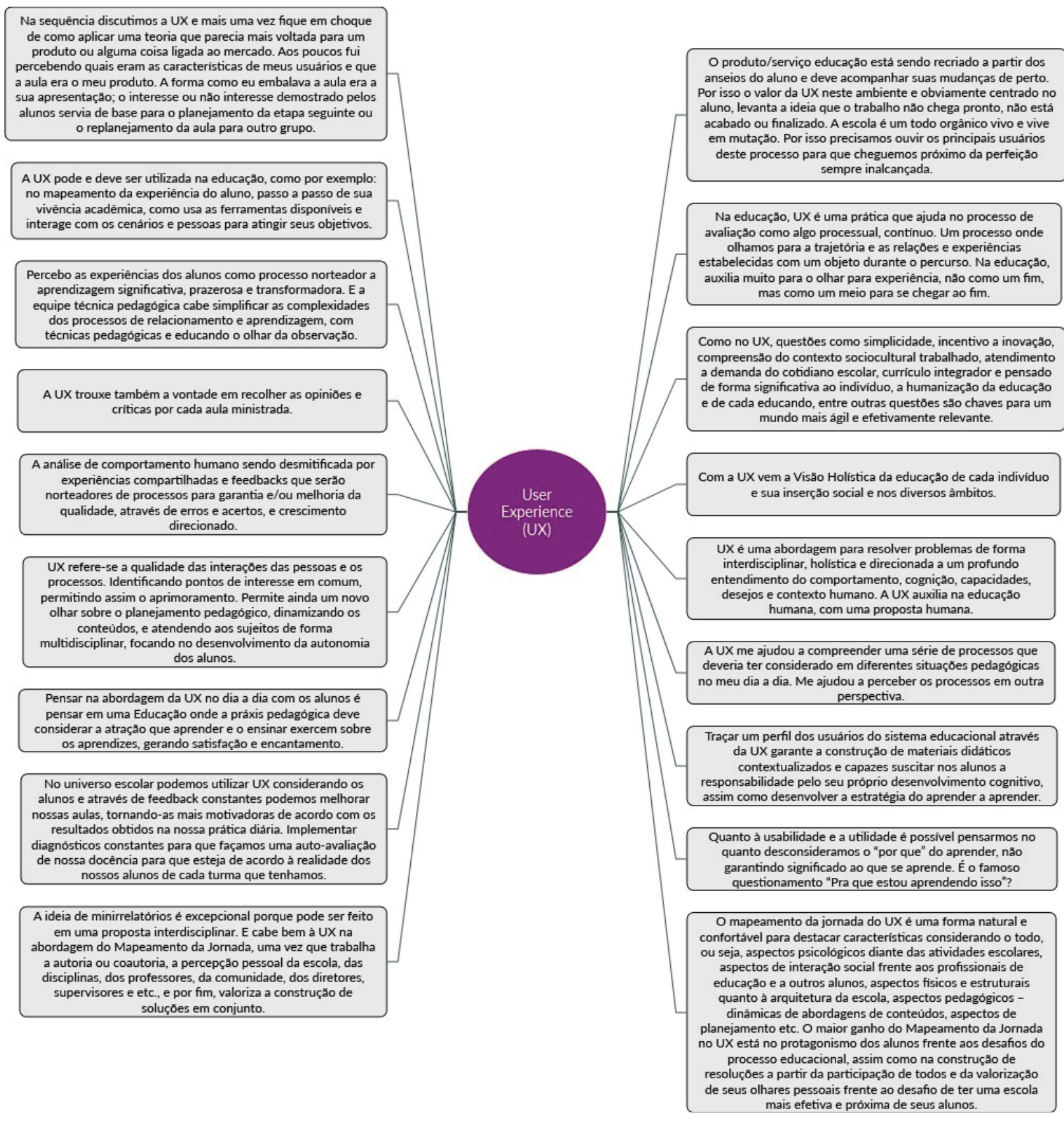

Figura 7: MMR dos cursistas sobre UX na Educação. 
O MMR com trechos dos textos dos cursistas sobre UX na Educação (Figura 7) no relatório final mostra a visão dos cursistas em relação ao tema e a reflexão em seus conteúdos e práticas pedagógicas.

\section{Análises complementares}

Com base nos 46 relatórios finais, fizemos algumas correlações em relação a gênero, área de atuação, nível de ensino em que atua, área de conhecimento, conhecimento prévio de DT e conhecimento prévio de UX, que são informações que foram solicitadas que os cursistas incluíssem no relatório. De todas as análises realizadas, uma mostrou um resultado curioso: Marcações por gênero (Figura 8). Segundo os dados, há um número maior de menções a DT por mulheres proporcionalmente em relação a menções a DT por homens, enquanto para tecnologia (e UX) há uma inversão (número maior de menções por homens). Talvez as razões estejam associadas com as mesmas de cursos de Computação usualmente atraírem maior número de homens, enquanto cursos de ciências sociais aplicadas geralmente um número maior de mulheres, mas isto deveria ser objeto de estudos futuros.

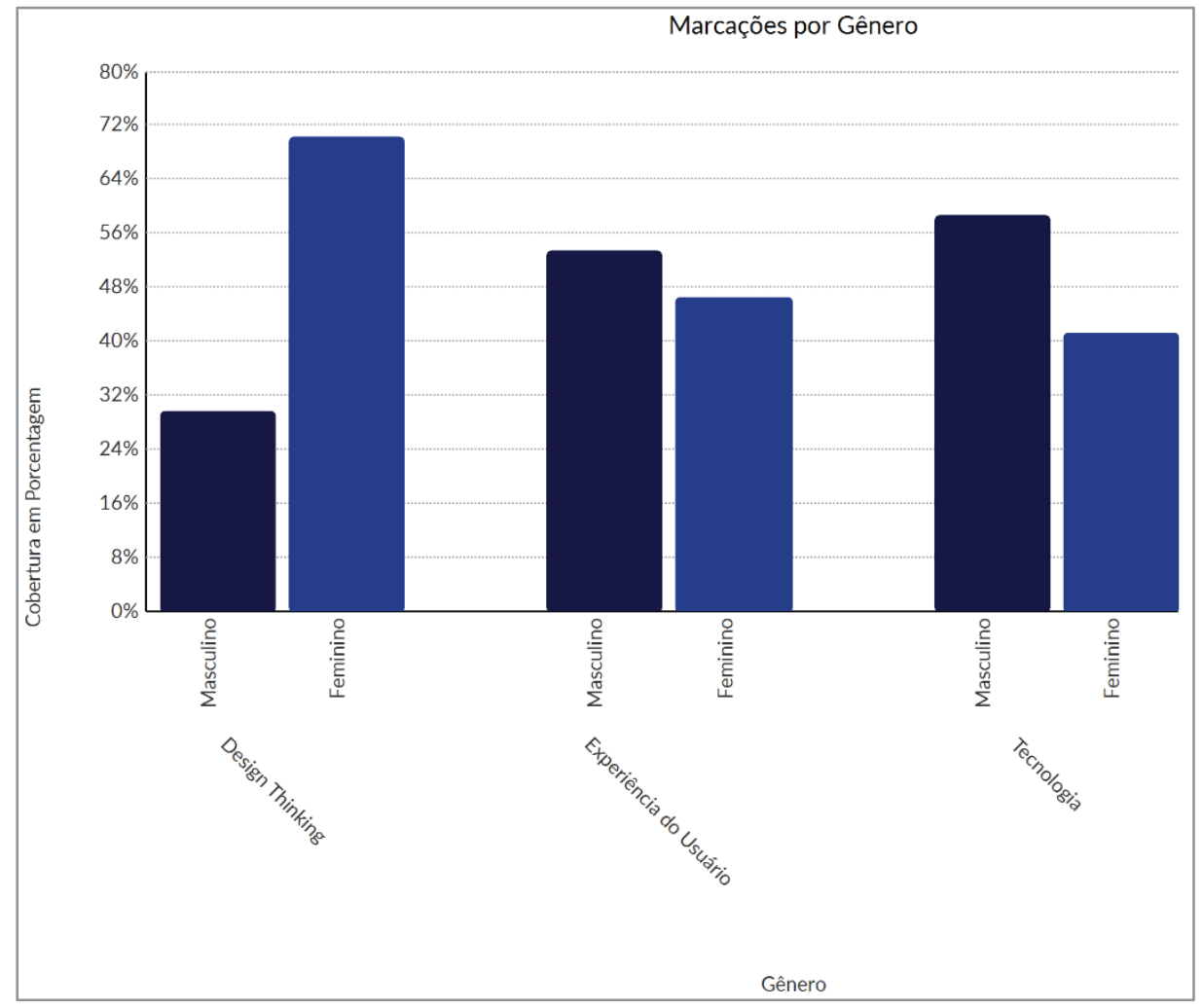

Figura 8: Marcações por gênero.

Além de uma codificação automática, as marcações (ou codificações) foram feitas manualmente duplamente. No caso de divergências, havia uma discussão para se chegar a um consenso. Por marcações (ou codificações), nos referimos a registrar nos documentos itens relevantes para seu entendimento e análise. As marcações definidas inicialmente foram: Tecnologia, DT e UX, que indicam os pilares desta pesquisa e que eram os itens que buscávamos analisar nos textos. Entretanto, a partir da leitura surgiram espontaneamente outros códigos, tais como aspectos pedagógicos, experiência com o curso, sentimentos e impacto na vida dos cursistas, em seus conteúdos e práticas pedagógicas e em seus alunos ou ambiente de trabalho. 
Todos cursistas comentaram em seus respectivos relatórios que foi importante discutir e trocar experiências e conhecimentos sobre as abordagens. A Figura 9 mostra o resultado da codificação automática para sentimentos positivos (lado esquerdo) e negativos (lado direito) que aparecem nas frases dos relatórios. É interessante que, embora se observe uma predominância de sentimentos positivos, também foram registrados sentimentos negativos. Ao analisar as causas dos sentimentos negativos, observou-se estarem relacionados ao estado emocional dos cursistas antes do curso em relação à profissão (principalmente professores que não conseguiam vislumbrar como trazer para suas aulas o que se estuda na educação, resultando em desmotivação nos professores e alunos). Comparando a marcação manual com a automática, observamos um número menor de sentimentos negativos nas marcações manuais, mas a diferença não é significativa. Identificamos que esta diferença se deve a existirem menções a termos negativos (resultando na classificação automática de sentimento negativo), mas que a frase como um todo tem uma conotação positiva, o que não foi registrado pelo processamento automático.

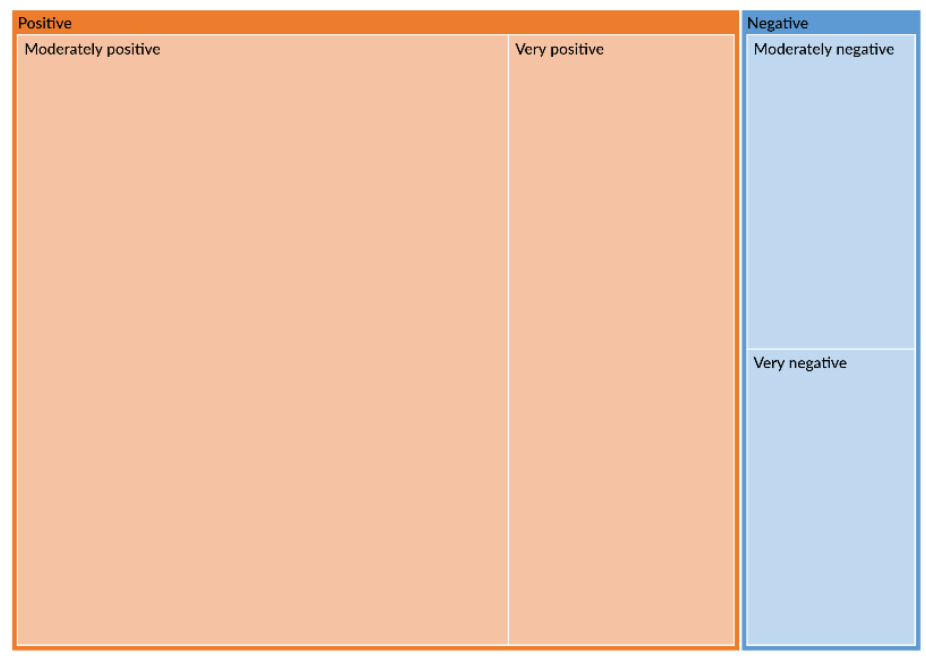

Figura 9: Marcações automáticas de sentimentos positivos (lado esquerdo) e negativos (lado direito) nos relatórios.

Os relatórios também indicam que as experiências de aprendizagem foram projetadas de diversas formas, confirmando a conjectura de variedade de aplicações na área de educação, tornando difícil imaginar uma fórmula específica de como aplicar DT e/ou UX no contexto educacional. Deste modo, a abordagem de explorar os conceitos, as fases e exemplos foi acertada, pois os professores puderam se apropriar deste conhecimento e aplica-lo em seus contextos específicos.

Nos 46 relatórios, encontramos 38 que mencionam reflexões e mudanças provocadas pelos três pilares, 16 mencionando que os três pilares promovem uma aprendizagem centrada no aluno, 14 indicando que promovem a aprendizagem significativa, 12 ressaltam o protagonismo dos alunos, 7 indicam que trazem elementos do cotidiano, além de outros ressaltarem características como interdisciplinaridade, educação inovadora, colaboração entre docentes e discentes e colaboração entre docentes. Este resultado, além de reforçar que os três pilares resolvem o problema de pesquisa, também apresenta achados para novos trabalhos que aprofundem tais aspectos.

Iniciamos a apresentação de trechos dos relatórios finais trazendo um relato que ilustra os questionamentos dos cursistas, a instigação para problematizar as histórias da vida que levam os professores a desenvolverem suas ideias e realizar mudanças em suas práticas, apresentando a relevância desta pesquisa-formação, embora não seja possível trazer toda a construção realizada por e com todos os cursistas. 
"Sei que pode parecer estranho para o professor, mas você não tem ideia da revolução que estes assuntos estão me proporcionando. Não paro de pensar como posso melhorar minhas aulas e como posso aplicar tudo que aprendi no curso. (...) Não acreditei que fosse aprender realmente algo que pudesse contribuir para o meu dia a dia de trabalho em sala de aula. Estou surpresa! E não tenho dúvidas de tamanha contribuição de tudo o que foi discutido e proposto nas aulas. (...) Anotei tudo (...) para saber o que acontece no mundo digital que pode contribuir para minhas aulas ficarem mais animadas. (...)" (depoimento de um cursista)

Com relação ao conteúdo abordado no curso, especificamente sobre tecnologias, os relatórios indicam uma boa aceitação sobretudo devido ao rico material disponibilizado e as discussões sobre o assunto.

"Tudo aquilo que nos foi oferecido [comentando sobre o material do curso] representou uma mudança de paradigma em relação às novas tecnologias que surgiram na sociedade nos últimos tempos, esclarecendo o funcionamento de inúmeros aparelhos e funcionalidades que estão presentes no nosso cotidiano, sem que, muitas vezes, tenhamos percebido isso. Estamos cercados por uma série de possibilidades de aplicação das novas tecnologias ao ensino, o que, necessariamente, não implica no aumento dos custos com a educação ou na aquisição de equipamentos de última geração para as escolas; (...) esta nova fase do processo de ensino-aprendizagem implica, sobretudo, na mudança de postura do mestre em relação aos novos meios de interlocução entre ele $e$ seus alunos, em virtude da possibilidade quase infinita de comunicação e cocriação de conhecimentos por meio da interatividade e do hipertexto." (depoimento de um cursista)

O uso de tecnologias e abordagens projetadas para promover o nível de desafio ideal influenciou positivamente a absorção cognitiva dos cursistas. Também serviu para promover feedback influenciando positivamente a absorção cognitiva, de acordo com a avaliação dos impactos de design segundo Zhang e Venkatesh (2018). Um cursista relata sobre seu compromisso com a prática educacional e o olhar a partir do aluno:

"A rica troca de conhecimento que me levou a refletir como a tecnologia vem sendo utilizada na educação, se ela vem contribuindo para um processo de aprendizagem mais motivador, participativo, colaborativo e, se seu uso é adequado e contextualizado a realidade dos alunos. Conclui que temos muito que caminhar sobre o uso das tecnologias da informação e comunicação na educação, mas para isso nós educadores precisamos nos capacitar, conhecer e saber como usá-la na prática educacional." (depoimento de um cursista)

Outro cursista foi mais específico:

"Ferramentas que agora podem dinamizar as aulas, trazer pra perto o aluno e oferecer um campo de pesquisa coletiva, mas com apreensões pessoais, mergulhar no universo do conhecimento não mais como passivos agentes do saber, mas sujeitos do processo, caminhando ao encontro do objeto com maior segurança e interesse. A ferramenta que antes não conhecia e fiquei entusiasmado para colocá-la em prática em minhas aulas foi o PADLET. (...) Como professor de História vi uma 
grande oportunidade de trazer o aluno para minha linha de raciocinio em relação ao conteúdo e dar liberdade para o questionamento, para a desconstrução e reconstrução da narrativa histórica. Com ele as atividades e tarefas passadas aos alunos ficam mais interessantes, a pesquisa mais rápida e sem aquela ideia de cópia de trabalho de terceiros. O painel é autêntico, feito em tempo real com auxílio do professor e colaboração de todos. Com esta ferramenta pude desenvolver dois novos projetos para minhas aulas. Com ela elaborei duas atividades com o tema 'História do Brasil Colonial' completamente interativas, atualizadas e empolgantes para mim e meus alunos." (depoimento de um cursista)

A partir do que foi realizado no curso e com os resultados obtidos, a proposta feita aos cursistas de aplicar DT e UX em seus respectivos contextos de trabalho em educação foi plenamente possível de ser atingido, fato este que caracteriza de forma positiva esta experiência de aprendizagem. Conforme relata um cursista:

"O curso em si trouxe uma nova luz sobre a minha didática. Comecei a ter várias ideias de como trabalhar meus conteúdos dentro dessa nova didática. Um exemplo, já está sendo utilizada na escola, nos nossos concelhos de classe, estamos utilizando a ferramenta experiencia do usuário para avaliar a didática do professor e melhorar o ensino." (depoimento de um cursista)

Outro cursista relata:

"Estou certa de que irei utilizar DT, aliás, já estou aplicando com meus alunos de $2^{a}$ e $3^{a}$ séries. Como fiquei muito atraída pelo assunto UX, resolvi ao final do $1^{\circ}$ bimestre colocar para os alunos minha proposta de trabalho para o periodo seguinte e perguntei o que achavam. Fiz questão de ouvir a todos." (depoimento de um cursista)

Os resultados indicam que os cursistas entenderam a proposta de empatia, de se colocar no lugar de outra pessoa, compreender sentimentos, desejos, ideias e ações de outro indivíduo, neste caso os alunos.

"A primeira semana foi para conhecer os colegas de curso - fase de empatia - e discutir sobre as experiências pessoais em sala de aula ou em outros espaços. O fórum intitulado 'Cheguei na turma' foi a ferramenta usada pelo tutor para permitir que cada cursista se apresentasse, assim como o fórum 'Minha prática' garantiu a troca de experiências. Esta primeira etapa foi importante porque pude perceber que há um grande interesse por parte dos profissionais da Educação em sair do lugar comum e se lançar na construção de novos caminhos, tendo como pavimentação, agora, as tecnologias e suas vertentes". (depoimento de um cursista)

Nesta perspectiva, o estudo de UX no curso foi relacionado com a experiência dos professores ao proporcionar uma experiência para seus alunos, identificando todos os aspectos da interação do aluno nas respectivas propostas desenvolvidas, como indicado em (Buley, 2013). A maioria dos cursistas declarou que essa experiência vivenciada no curso foi rica, além de sinalizar o desejo de utilizar DT e UX em seus respectivos contextos de trabalho, foi possível identificar os benefícios de uma Experiência de Aprendizagem no curso. Um cursista relata:

"As semanas que vivenciei nesse curso expandiram minha visão como educador, e estreitou muito mais a pedagogia que aprendi na 
minha graduação de licenciatura com os conhecimentos que já tinha como desenhista publicitário e artístico." (depoimento de um cursista)

Diversos outros relatos indicam o uso de DT e UX a partir do curso, em suas atividades, dos quais destacamos:

“(...) Os conceitos de DT e UX passaram a fazer parte do projeto de implementação dos $20 \%$ da educação a distância nos cursos presenciais na instituição onde trabalho." (depoimento de um cursista)

Também trazemos este trecho do relato de outro cursista:

"Vamos colocar em nosso aplicativo uma ferramenta para implantar a experiência de usuário UX. Será um ícone de UX onde poderemos ter as sugestões e comentários no App. (...)Por isso, o uso da $U X$ será relevante durante todo o ano escolar para que ao final de cada ano letivo tenhamos como mensurar os resultados (...)." (depoimento de um cursista)

A colaboração entre professores leva ao desenvolvimento profissional e à satisfação acadêmica. O curso estruturado de maneira a maximizar a discussão colaborativa entre os professores propiciou condições favoráveis ao crescimento e desenvolvimento dos cursistas. $\mathrm{O}$ incentivo às discussões nos fóruns e trocas com os colegas, refletindo sobre suas crenças e práticas pedagógicas, colaborou para trocas de experiências de aprendizagem bem sucedidas e propícias à construção do conhecimento. Conforme relata um cursista:

"Precisamos apoiar e promover espaços de escuta, trocas, criação e efetivos projetos não apenas para o desenvolvimento do aluno, como também para a melhoria do ambiente onde estamos inseridos, a escola." (depoimento de um cursista)

Esses resultados evidenciam a utilização de novas tecnologias, juntamente com as abordagens de DT e UX como um caminho eficaz para apoiar professores que desejam inovar e investir em seu desenvolvimento profissional, além de poder contribuir na eficácia do ensino, resolvendo problemas por meio de reflexão, discussão colaborativa e trocas de experiências de aprendizagem utilizando novas tecnologias e recursos digitais, confirmando os achados de Nameghi e Sheikhahmadi (2016).

\section{Conclusão}

Nossa pesquisa investigou as reflexões e mudanças nos conteúdos e práticas docentes de cursistas em uma iniciativa de formação docente, com base em tecnologias, DT e UX. Estes três pilares da pesquisa foram investigados através de uma pesquisa-formação. Como resultados, observamos que enquanto um olhar para as tecnologias motivou os professores a revisarem seus conteúdos e práticas, o contexto do DT apoiou ideias, construções de conhecimento e práticas pedagógicas, projetos e inovações pessoais, tanto em salas de aula como em contextos educacionais mais amplos (como revisão de modelos de ensino online e híbrido, revisões de projetos políticos-pedagógicos, revisões de metodologias e abordagens didáticas, revisões processuais de reuniões etc.). Complementarmente, a utilização do UX possibilitou trazer um melhor entendimento dos alunos, reforçar o propósito das práticas educacionais e da aprendizagem, bem como melhorar a qualidade do ensino e da aprendizagem. Estes achados indicam a aproximação da prática docente com a realidade dos alunos, integrando-os para uma melhor experiência de aprendizagem (resolução do problema de pesquisa) e comprovam as 
bases teóricas utilizadas para fundamentar a proposta (da relevância dos três pilares no contexto educacional: tecnologia, DT e UX).

Pelos relatos no curso, no início os cursistas não se viam como designers, mas passaram a se ver dessa maneira, através das trocas e da experiência com práticas de DT e UX. Além disto, o foco em novas tecnologias propulsionou a visão prática, trazendo para os cursistas um formato de implementação das mudanças em suas práticas educacionais.

A pesquisa, abordando ativamente o ensino por meio de tecnologias, DT e UX levou os cursistas a verem o ensino com outras lentes, como uma prática criativa e centrada no aluno. Foi possível perceber o design como um caminho para a solução de problemas nas práticas educacionais. Os resultados apresentados pelos cursistas indicam que houve um ganho de qualidade ao discutir tecnologias e introduzir o DT e a UX. Como um aluno resumiu:

"Em suma, o curso foi altamente proveitoso e esclarecedor no que diz respeito ao 'como fazer' para estimular o aprendizado e tornálo significativo. Destaco as várias ferramentas das TIs e as diferentes plataformas que podem ser usadas no contexto educacional. Outra questão é a importância da formação continuada dos profissionais da Educação, assim como sua atualização em um mundo totalmente globalizado e imerso em tecnologias. 'Novas Tecnologias com Experiência do aluno: Design Thinking para educadores' garantiu uma motivação capaz de ratificar meu compromisso com a participação na mudança de paradigma do mundo da Educação." (depoimento de um cursista)

Observamos ainda achados teóricos e práticos que vão além da resolução do problema de pesquisa, ao resgatar a motivação do professor e sua percepção de que é possível instrumentalizar as bases das teorias educacionais que promovem a aprendizagem centrada no aluno, a aprendizagem significativa, o protagonismo dos alunos, os elementos do cotidiano, a interdisciplinaridade e colaboração, que contribuem para uma educação inovadora. Investigar estas contribuições em mais profundidade é objeto de trabalhos futuros.

Do ponto de vista metodológico, ressaltamos como contribuição uma abordagem de análise do discurso em pesquisa-formação com apresentação dos resultados da análise através de nuvens de palavras, mapas mentais de reflexões e trechos textuais de discurso. Embora seja possível observar alguns trabalhos usando as nuvens de palavras, neste artigo elas foram apresentadas com base na codificação dos relatórios dos cursistas em relação aos três pilares teóricos da pesquisa, apresentando a construção do conhecimento dos cursistas sobre os pilares na educação. Adicionalmente, os mapas mentais de reflexões representam uma novidade no contexto de pesquisa-formação e permitem observar os diferentes pontos de vista complementares dos cursistas sobre cada um dos pilares. Finalmente, os trechos textuais de discurso dos cursistas, embora seja uma prática comum neste tipo de trabalho, trazem uma riqueza particular nesta pesquisa pela ênfase motivacional (sentimentos) dos cursistas e os impactos da formação-docente.

Em termos de contribuições técnicas, podemos destacar o próprio curso de formação de professores. No ano seguinte à realização do curso, a Secretaria de Educação do Estado do Rio de Janeiro solicitou que ele fosse ofertado no cardápio de cursos de capacitação de professores da rede estadual, por considerar o conteúdo inovador e pertinente para discussões atuais com os profissionais de educação da rede.

Como limitação do trabalho, destacamos o fato de considerarmos apenas uma turma no processo de formação-docente e, portanto, o contexto restrito dos participantes. Diante desta limitação, consideramos cursistas de diferentes formações e áreas de atuação. Além disto, as 
interações entre os cursistas e a análise qualitativa possibilitaram capturar diferentes perspectivas e experiências, possibilitando ir além deste contexto restrito. Entre as limitações técnicas, estão os algoritmos utilizados para geração das nuvens de palavras, cujo processamento tinha restrições no tratamento sintático e semântico devido à ferramenta utilizada. O processo de codificação também possui restrições porque é sujeito a erros. De modo a lidar com estas limitações, consideramos um ajuste no dicionário de stopwords para apoiar a geração de nuvens de palavras e uma codificação manual dupla para minimizar os erros do processo.

Como trabalho futuro, além da investigação de outros aspectos pedagógicos observados complementarmente ao problema abordado neste estudo, fica a ideia de um novo ciclo de investigação com um universo maior de cursistas, com perfis distintos, apresentando e discutindo mais profundamente Learning Design (LD) e Learning Experience (LX), com possível desenvolvimento de um projeto mais consistente como atividade do curso por parte dos cursistas.

\section{Agradecimentos}

Este estudo foi parcialmente financiado pelo Conselho Nacional de Desenvolvimento Científico e Tecnológico $(\mathrm{CNPq})$, projeto: Searching as Learning: a busca de informação como ferramenta para a aprendizagem, processo: 315374/2018-7. Agradecemos a todos os envolvidos diretamente e indiretamente nesta pesquisa, em especial aos cursistas que contribuíram para o estudo, bem como a Heder Magalhães pela revisão da linguagem utilizada no texto para torna-la mais acessível aos leitores.

\section{Referências}

Aguado, G., Fernández, C., Garreta-Domingo, M., Griset, R., \& Valls, A. (2014). Course Sprints: Combining teacher training, design thinking and hackathons. Lecture Notes in Computer Science, 8523, 3-12. doi: 10.1007/978-3-319-07482-5_1 [GS Search]

Andersen, H. V., \& Pitkänen, K. (2019). Empowering educators by developing professional practice in digital fabrication and design thinking. International Journal of Child-Computer Interaction, 21, 1-16. doi: 10.1016/j.ijcci.2019.03.001 [GS Search]

Bastos, C., \& Siqueira, S. (2019). Uma Iniciativa de Formação Docente em Design Instrucional sob os enfoques de Design Thinking e Experiência do Usuário. Anais do Workshop de Informática na Escola, 25, 869-878. doi: 10.5753/cbie.wie.2019.869 [GS Search]

Bates, T. (2015). Teaching in a digital age: Guidelines for designing teaching and learning for a digital age. Tony Bates Associates.

Buley, L. (2013). The User Experience Team of One: A Research and Design Survival Guide. New York: Rosenfeld Media, 2013.

Buzan, T. (2005). Mapas mentais e sua elaboração. Editora Cultrix.

Clark, D. (2014). “Por Design Instrucional Sistema e ADDIE?”. Acesso em 13/04/2020. http://goo.gl/v5V2sA

Cross, N. (2011). Design thinking: Understanding how designers think and work. Berg.

DePaolo, C. A., \& Wilkinson, K. (2014). Get your head into the clouds: Using word clouds for analyzing qualitative assessment data. TechTrends, 58(3), 38-44. doi: 10.1007/s11528-014$\underline{0750-9}$ [GS Search] 
Dunne, D., \& Martin, R. (2006). Design thinking and how it will change management education: An interview and discussion. Academy of Management Learning \& Education, 5(4), 512-523. [GS Search]

Ferreira, M. N. F., da Cruz Pinheiro, F., von Wangenheim, C. G., Missfeldt Filho, R., \& Hauck, J. C. R. (2020). Ensinando Design de Interface de Usuário de Aplicativos Móveis no Ensino Fundamental. Revista Brasileira de Informática na Educação, 28, 48-72. doi: $\underline{10.5753 / \text { rbie.2020.28.0.48 [GS Search] }}$

Filippo, D., Pimentel, M., \& Wainer, J. (2011). Metodologia de pesquisa científica em sistemas colaborativos. Sistemas Colaborativos, 1, 379-404. Elsevier Brasil.

Foulger, T. S., Graziano, K. J., Schmidt-Crawford, D., \& Slykhuis, D. A. (2017). Teacher educator technology competencies. Journal of Technology and Teacher Education, 25(4), 413-448. https://www.learntechlib.org/primary/p/181966/

Henriksen, D., Richardson, C., \& Mehta, R. (2017). Design thinking: A creative approach to educational problems of practice. Thinking skills and Creativity, 26, 140-153. doi: 10.1016/j.tsc.2017.10.001 [GS Search]

Huang, R., Spector, J. M., \& Yang, J. (2019). Educational Technology: A Primer for the 21st Century. Springer.

Interaction Design Foundation (IDF, 2016). Learning Experience Design - The Most Valuable Lessons. Released on November 2016. Acesso em 13/04/2020. https://www.interactiondesign.org/literature/article/learning-experience-design-the-mostvaluable-lessons

Josso, M. C. Experiências de vida e formação. São Paulo: Cortez.

Kilgore, W. (2016). UX to LX: The Rise of Learner Experience Design. Acesso em 13/04/2020. https://www.edsurge.com/news/2016-06-20-ux-to-lx-the-rise-of-learner-experience-design

Kirschner, P. A. (2015). Do we need teachers as designers of technology enhanced learning?. Instructional science, 43(2), 309-322. doi: 10.1007/s11251-015-9346-9 [GS Search]

Mishra, P., \& Koehler, M. J. (2006). Technological pedagogical content knowledge: A framework for teacher knowledge. Teachers college record, 108(6), 1017-1054. [GS $\underline{\text { Search }] ~}$

Nameghi, S. A. O., \& Sheikhahmadi, M. (2016). From Teacher Isolation to Teacher Collaboration: Theoretical Perspectives and Empirical Findings. English Language Teaching, 9(5), 197-205. [GS Search]

Norman, D.A. (1982). Learning and Memory. San Francisco: W.H. Freeman \& Company.

Norton, P., \& Hathaway, D. (2015). In search of a teacher education curriculum: Appropriating a design lens to solve problems of practice. Educational Technology, 3-14. [GS Search]

Oliveira, J., \& Andrade, A. (2019). Proposta de um Modelo Inovador de Formação de Professores baseado no Design Thinking. Anais dos Workshops do Congresso Brasileiro de Informática na Educação, 8, 692-700. doi: 10.5753/cbie.wcbie.2019.692 [GS Search]

Raybourn, E.M. (2016). A Metaphor for Immersive Environments: Learning Experience Design Challenges and Opportunities. MODSIM World 2016, Paper No. 47. [GS Search]

Ribeiro, A., Longaray, A., \& Behar, P. (2012). Práticas Criativas na Web 2.0: a construção de um objeto de aprendizagem. Anais do Simpósio Brasileiro de Informática na Educação SBIE, 22, 313-320. [GS Search] 
Ruggiero, D., \& Mong, C. J. (2015). The teacher technology integration experience: Practice and reflection in the classroom. Journal of Information Technology Education, 14, 161-178. doi: $10.28945 / 2227$ [GS Search]

Santos, R., \& Santos, E. O. (2015). Pesquisando nos cotidianos da cibercultura: uma experiência de pesquisa-formação multirreferencial. Revista da FAEEBA-Educação e Contemporaneidade, 24(44).

Silva, M. (2005). Docência interativa presencial e online. In: Valentini,Carla Beatris; Schelmmer, Eliane. (Org.). Aprendizagem em ambientes virtuais: compartilhando ideias e construindo cenários. Caxias do Sul: Educs. [GS Search]

Silva, P. A., \& Cavalcante, P. S. (2016, November). Orquestrando processos didáticos com Design Thinking. Anais dos Workshops do Congresso Brasileiro de Informática na Educação, 5, 540-549. doi: 10.5753/cbie.wcbie.2016.540 [GS Search]

Simon, H. A. (1969). The sciences of the artificial. Cambridge, MA.

Stefaniak, J. (2020). The Utility of Design Thinking to Promote Systemic Instructional Design Practices in the Workplace. TechTrends, 64(2), 202-210. doi: 10.1007/s11528-019-00453-8 [GS Search]

Tondeur, J., Van Braak, J., Ertmer, P. A., \& Ottenbreit-Leftwich, A. (2017). Understanding the relationship between teachers' pedagogical beliefs and technology use in education: a systematic review of qualitative evidence. Educational Technology Research and Development, 65(3), 555-575. doi: 10.1007/s11423-016-9481-2 [GS Search]

Zhang, X., \& Venkatesh, V. (2018). From design principles to impacts: A theoretical framework and research agenda. AIS Transactions on Human-Computer Interaction, 10(2), 105-128. doi: $10.17705 / 1$ thci.00106. [GS Search]

Watson, A. D. (2015). Design thinking for life. Art Education, 68(3), 12-18. [GS Search] 